\title{
ÉTICA Y MORAL SOCIAL EN LA OBRA DRAMÁTICA DE SERGIO VODANOVIC
}

\author{
POR \\ Juan ANdrés Piña
}

Desde mediados de los años cincuenta aproximadamente, irrumpió en Chile una significativa generación de dramaturgos que durante esa década y la siguiente entregó una importante cantidad de obras, la mayoría de las cuales ha pasado a ser algo así como "clásicos" del teatro chileno. No solamente la cantidad de estrenos es destacable, sino también la complejidad y variedad de ellos. Por primera vez, quizás, se puede hablar de una "generación de autores" dramáticos, es decir, un conjunto de voces que en un mismo período responden a inquietudes parecidas y guardan posiciones similares respecto de lo que debe ser el teatro, su valor y su función en una comunidad.

Con el amparo y el apoyo de los hacía poco fundados teatros universitarios, primero, y las compañías privadas después, estos autores se sintieron afines con la renovación escénica chilena de aquello años, vinculándose con nuevas formas teatrales y con grupos que estaban en condiciones - técnica y artísticamente- de estrenar sus obras.

Muchas expresiones aparecen por aquellos años. Entre ellas, la de un teatro de búsqueda individual, centrado en las personas, en sus anhelos y en su posición en el mundo, en su soledad, incomunicación, en sus preguntas trascendentales y ansias de absoluto. Muchas de estas creaciones están dominadas por la corriente del realismo sicológico, que engarza directamente con la generación literaria de $1950 \longrightarrow 1957-$ y que incluye a narradores como José Donoso, Guillermo Blanco, Jorge Edwards, Enrique Lafourcade.

Una de sus características fue la superación de un criollismo ya agónico, la búsqueda de temas nuevos, como la vida del hombre en la ciudad, la soledad y el desamor, y cuyas técnicas narrativas rompen con el tradicional realismo. Entre los dramaturgos de esta corriente destacan Luis Alberto Heiremans (El abanderado, Versos de ciego, El toni chico), muchas de las obras de Egon Wolff (Niñamadre, Mansión de lechuzas, Flores de papel), e incluso de Jorge Díaz, estudiado casi siempre como un puro autor "del absurdo" ( $E l$ cepillo de dientes, Réquiem por un girasol, El génesis fue mañana). Otro es Alejandro Sieveking, sobre todo en sus primeras obras, fuertemente influidas por el drama sicológico. Son el caso de Mi hermano Cristián, Cuando no está la pared y Parecido a la felicidad.

Aunque en la misma línea anterior, pero con plantamientos políticos más directos, hay una serie de obras de la dramaturgia chilena que se refieren a las demandas de las clases desposeídas, a los anhelos de los sectores postergados, a la lucha de estos grupos por cumplir sus deseos de mejor distribución económica y de justicia social. A la vez, 
critican ácidamente a las instituciones burguesas y proponen cambios muchas veces revolucionarios. Es Isidora Aguirre quien más trató este tema durante las décadas del cincuenta y sesenta (Población Esperanza, Los papeleros, Los que van quedando en el camino). En Fernando Cuadra también se evidenció una corriente de denuncia de las miserables condiciones de vida de los sectores más pobres, a través de obras como Los sacrificados, La niña en la palomera y Doña Tierra.

Otra tendencia la constituyen aquellas obras de recuperación del pasado histórico, de los mitos fundacionales del país y de la búsqueda de un folklore estilizado que revelara las leyendas y las tradiciones chilenas, pero con renovados puntos de vista. Hasta Pablo Neruda entró en este terreno con la recuperación del mito y la historia de Joaquín Murieta, en la obra homónima estrenada en 1967, donde narra las peripecias del bandido chileno en California.

María Asunción Requena es quien representa mejor este punto de vista, sobre todo en Ayayema, Fuerte Bulnes y Chiloé, cielos cubiertos. Fernando Debessa incursionó en los aspectos históricos del pasado chileno en obras como Mama Rosa, O'Higgins y El guerrero de la paz.

\section{Problema MORAL Y CONDUCTAS ÉTICAS}

Finalmente hay una tendencia fuerte y claramente dominante entre la producción de estos dramaturgos: aquellas obras que critican éticamente los valores heredados y las ideologías que sustentan las clases, las familias o las instituciones sociales. Se trata comúnmente de un teatro realista que opone al individuo, con sus ideales y sus anhelos, frente a una institucionalidad avasalladora. Es decir, muchas veces el conflicto se establece entre las convicciones individuales -que son el reflejo de la aspiración social, muchas veces moralizante- y la superestructura de la sociedad. Obras como Los invasores, de Wolff, Topografia de un desnudo, de Díaz, Tres tristes tigres, de Sieveking, El prestamista, de Fernando Josseau y El wurlitzer, de Juan Guzmán, representan claramente esta línea.

Una característica común está presente aquí y aparece en la mayoría de los autores: la preocupación por el tema moral, por las conductas éticas de las personas en sus vidas públicas y privadas.

Sergio Vodanovic (nacido en 1926 y de profesión abogado) es seguramente quien con mayor fuerza representa esta posición. Además, en el panorama de esta nueva dramaturgia chilena, las obras de Vodanovic encarnan una de las propuestas características del teatro de aquella época. Sus creaciones se enmarcan habitualmente en un realismo que consigue un equilibrio entre los aspectos sociales, y los individuales o sicológicos. Sus personajes poseen un sello muy definido en relación al comportamiento cotidiano, son homologables a la "vida real", y sus personalidades son fácilmente identificables. En este sentido, son de un perfil característico del realismo sicológico.

Pero, simultáneamente, los conflictos a que están sometidos no quedan encerrados en sus individualidades más inmediatas, sino que son reflejo de una problemática que atañe a toda la sociedad: a través de sus protagonistas, estas obras se interrogan, ponen en tela de juicio las bases del funcionamiento social, las instituciones, la política, el aparato público, el desempeño de los funcionarios gubernamentales y los conceptos sobre los cuales se 
afirma un país y una sociedad. No es extraño que el mismo Vodanovic reconozca la herencia ibseniana en sus producciones, y que hacia mediados de la década del sesenta declarara ya no satisfacerle. ${ }^{1}$

Así, el teatro de Sergio Vodanovic está animado por la intención de develar o revelar aquello que ocultan las apariencias, delatar el funcionamiento efectivo de las personas y de las organizaciones. En esta perspectiva, muchas de sus creaciones entregan una mirada crítica, rozando muchas veces lo que se ha denominado Teatro de Tesis: el que plantea, en diálogos esencialmente expositivos, un punto de vista, una idea, una ideología sobre el funcionamiento de esta sociedad que quiere reflejar.

$\mathrm{Y}$ dentro de estas preocupaciones, el tema ético o moral ocupa un lugar preferente. En efecto, aquí se enjuicia si el comportamiento de estos "héroes" de la sociedad es correcto, de acuerto a lo que se supone debe ser su conducta pública y personal.

La primera obra suya donde ello aparece es en El senador no es honorable (1952). Solamente el título ya es clarificador de las intenciones del autor. En la obra, un joven abogado debe reemplazar a su padre en la carrera política al momento de fallecer aquél. $\mathrm{Al}$ poco tiempo, el protagonista descubre que su padre no era ese hombre intachable y limpio que el resto suponía, sino alguien que utilizaba su cargo público para actividades sociales y económicas inescrupulosas. El conflicto del hijo — suceder a su padre en la vida política y también en los dudosos negocios- es más o menos típico a los personajes de Vodanovic: actuar por el bien de la sociedad o aprovechar de su posición para el lucro y la satisfacción personal.

Deja que los perros ladren -estrenada en 1959 y una de las obras chilenas más exitosas del período- es el paradigma de esta tendencia y marca una profundización del tema anunciado en su pieza anterior. En ella Esteban, el jefe del Departamento de Salubridad de un ministerio, ha actuado siempre conforme a sus convicciones y a lo que su conciencia le dictaba, sin ocupar jamás su puesto para beneficio personal. Pero en un momento su amigo, el Ministro, le obliga a firmar un decreto que supone la clausura inmediata de un periódico opositor. Si no lo hace, sobre Esteban pesa la amenza de quedar cesante.

Accede entonces el protagonista a dicho cierre y a partir de allí se enreda en una espesa red de negociados, arreglos y componendas, y donde el Ministro es un hábil jugador. Así, el protagonista conoce la verdadera cara que se oculta tras la fachada, los auténticos "pilares de la sociedad", según diría Ibsen. En fin, una sociedad descompuesta ha traicionado los ideales de Derecho, Ley y Moralidad sobre los que fue fundada.

Deja que los perros ladren cimentó su éxito en apelar a una situación nacional que el autor miró con ojos críticos: la pérdida de los ideales de una generación intelectual que hacia 1940 conquistó el poder a través del Frente Popular. Ellos, los jóvenes de entonces, propusieron y llevaron a cabo una modernización nacional basada en lo que se llamó el Estado de Compromiso, donde Chile logró un desarrollo económico y social gracias al apoyo estatal. En su desenlace, la obra es un llamado precisamente a rescatar aquel ideal.

Igual reflexión se advierte en Nos tomamos la universidad, basada en un suceso chileno auténtico ocurrido en 1967, cuando un grupo de estudiantes de la Universidad Católica se

\footnotetext{
' Sergio Vodanovic, "Experiencias de un autor", ("El teatro y sus problemas en Chile"), Aisthesis 1
} (Santiago: Universidad Católica de Chile, 1966) 103. 
apoderó de su sede central, con el objeto de presionar a las autoridades académicas para que se efectuara la tan anhelada reforma. Aunque tales reformas efectivamente se realizaron, la mirada teatral de Vodanovic es desencantada: cuando los estudiantes han triunfado en su movimiento, el grupo organizador se une a la mediocridad que aún sigue en poder, consigue cargos académicos y renuncia blandamente a los principios por los que ayer luchaba, traicionando a los jóvenes que en la base lucharon por los cambios.

Un personaje clave de la obra es Arnaldo, estudiante ya mayor. Con él, Vodanovic representa las progresivas "traiciones históricas" de los gobiernos chilenos desde 1940 en adelante. El padre de Arnaldo fue un luchador del Frente Popular, aunque el hijo sabe que sólo lo hizo para conseguir un cargo en el gobierno, esperanzas que se frustaron a lo largo de los años. Incluso Arnaldo vio llegar a la Democracia Cristiana al poder en 1964, y al poco tiempo se desencantó.

En este sentido, la visión del autor es que cuando se impone una tesis, cuando un movimiento gana sus propuestas, este triunfo llevará aparejada, necesariamente, la corrupción y la deslealtad al ideal que los inspiró. De ahí que en estas obras las luchas de los protagonistas sean individuales, personajes prácticamente solitarios que se marginan y cuyo mensaje queda vibrando en el aire, como una acusación al colectivo que se acomodó a las formas de uso.

En Nos tomamos la universidad, Arnaldo sigue peleando -en una mezcla de ingenuidad y misticismo, y con métodos casi infantiles - por algo que en el fondo sabe que está perdido. Se aferra casi adolescentemente a los ideales juveniles, aunque sabe que con los años serán disueltos. Le dice a uno que sus compañeros de toma: " ¿Sabes lo que a todos nos espera en un par de años más? Seremos profesionales, saldremos de la universidad. ¿Para qué? Para integrarnos a la sociedad, a esa sociedad que ahora nos parece hipócrita, injusta, podrida. Y principiaremos a ganar dinero; tendremos autos, casas, hijos ... ¡Y habrá que defender todo eso! Entonces, entonces recordaremos esta toma como una aventura juvenil, idealista". ${ }^{2}$ Arnaldo se queda, entonces, enredado en estas luchas universitarias y no hace lo que todo el mundo, por el terror a contaminarse, por el miedo a perder esos sueños.

UNA SOCIEDAD AL DESNUDO

Perdón ... jestamos en guerra! (1966) es otro ejemplo claro de esta línea teatral, obra atravesada por un tono humorístico y de comedia que aliviana adecuadamente su presentación. La acción cuenta la historia de un pueblo ocupado por los invasores en tiempos de guerra. Entre ellos sólo hay viejos y mujeres, los que viven angustiados sin comida ni bebida. Deciden entonces montar un cabaret a través del cual obtendrán información del enemigo y adquirirán provisiones, que son el importe por asistir a las funciones. La idea nace como un ideal patriótico para ayudar a los aliados, pero a medida que la acción avanza su objetivo se desvirtúa y refleja las verdaderas intenciones de los protagonistas.

${ }^{2}$ Nos tomamos la universidad (Santiago: Editorial Universitaria, 1972) 126. 
De esta manera, las mujeres, al principio reticentes para desvestirse en público, después se pelean entre ellas por hacerlo. Su inicial pudor y moralidad se convierten en vanidad. Entre los personajes hay dos marginados, Daniel y Elba. Ella no quiso desnudarse frente a las tropas enemigas y él se negó a asistir a las funciones, por encontrarlas denigrantes. Por lo mismo, ambos son acusados de traición al no apoyar a las fuerzas patrióticas y son sometidos al duro dictamen de un tribunal.

La injusticia es evidente: los "leales" que organizaron el cabaret sólo lo hicieron por sus propios intereses e incluso las mujeres entraron en flagrantes relaciones con algunos oficiales enemigos. En el juicio, Daniel es condenado, y así sirve como chivo expiatorio por la pérdida de la guerra.

En Perdón ... jestamos en guerra!, Vodanovic no intenta hacer un alegato antibelicista, sino entregar una mirada entre áspera y humorística sobre la falta de escrúpulos que esconde la institucionalidad. Incluso el autor juega graciosamente con la retórica que envuelve a los representantes del orden y la moral. Ello aparece en un elemento paródico clave de la obra: la letra del himno nacional que todos cantan entusiasmados: "Por la Patria ofrendamos la vida/ La vida, el alma y el bienestar./ Nos negamos a nosotros mismos/ en aras de la sociedad/ en aras de la sociedad". ${ }^{3}$

Sergio, uno de los organizadores del cabaret, es el único que tiene lucidez respecto a las verdaderas intenciones que animan a quienes representan la oficialidad. En toda esta maraña de componendas e hipocresías, sólo parecen salvarse algunos personajes puros, pero que al final son siempre sacrificados.

El asunto de desvestirse en Perdón ... jestamos en guerra! - las mujeres "patrióticas" van dejando sus prendas alegremente en el escenario creado para los enemigos - no es casual. Método teatral o tema dramático, éste es una clave para entender la obra de Vodanovic: casi siempre la desnudez que va surgiendo está asociada a otra, una especie de "desnudez del espíritu" o quedar en evidencia, que es metáfora de ese revelar lo que ocultan las apariencias de la que se hablaba antes.

Ello es claro en la triología formada por Viña (subtitulada "Tres obras en traje de baño", nada menos): El delantal blanco, La gente como nosotros y Las exiliadas (1964). ${ }^{4}$

En la primera, una mujer de clase alta humilla a su empleada doméstica con quien va a la playa, ofreciéndole cambiar su elegante traje de baño por el tosco delantal de la muchacha. La tesis de la señora es que el trastoque en nada afectará la apariencia, porque siempre se reconocerá la clase, a pesar de la vestimenta. Ocurre, claro, lo contrario, y más allá de la anécdota de comedia que rodea la situación, la obra critica a una clase social fundada sobre sus atavíos exteriores.

Desnudamiento también hay en Gente como nosotros, que hace convivir a dos parejas producto de un percance caminero: el matrimonio de clase social alta y dos muchachos modestos. Simbólicamente la joven es striptisera, con lo que se refuerza esta atmósfera de quedar al desnudo ante los ojos del otro. La conversación de los cuatro personajes muestra

${ }^{3}$ iPerdón ... Estamos en guerra!, Teatro chileno contemporáneo (Antología) (Madrid: Fondo de Cultura Económica y Centro de Documentación Teatral, 1992).

${ }^{4}$ La versión utilizada aquí es la publicada por Editorial Pehuén, Santiago, 1990. 
a seres bastante patéticos y frustrados, distintos a lo que aparentan: deseosos de amor, inseguros y fracasados, tanto en sus oficios como en vidas personales.

Las exiliadas, en fin, es la obra más compleja de la trilogía y la más estudiada, cuya estética está liberada del excesivo realismo que preside a las anteriores. En ella, una anciana aristócrata en silla de ruedas y su hija toman el sol en un rincón de la playa, donde han sido confinadas por las nuevas generaciones de clase media. También se trata de personajes prisioneros en una rígida formalidad y ausencia de vida. Tanto, que la madre muere en el desarrollo de la acción y la hija toma el puesto. En la visión del autor, se trata de un grupo social que no tiene futuro y cuyos valores y estilo han perdido vigencia.

Develación de un mundo sobre el cual debe surgir otro -aunque haya que esperar y los cambios sean abatidos por sucesivas corrupciones-es el tema que parece atravesar las obras de Sergio Vodanovic, síntesis de otras creaciones de la rica dramaturgia chilena del período. 